\title{
The recovery of the Shuram anomaly and paleoproductivity balance
}

\author{
Fuencisla CAÑAdas ${ }^{1 *}$, Dominic PAPINEAU ${ }^{1,2,3}$, \\ MELANIE J. LENG ${ }^{4}$, AND GRAHAM SHIELDS ${ }^{1}$
}

${ }^{1}$ Department of Earth Sciences, University College London, London, UK (*corresp: fuencisla.canadas.16@ucl.ac.uk) ${ }^{2}$ London Centre for Nanotechnology, University College London, London, UK

${ }^{3}$ Centre for Planetary Sciences, University College London \& Birkbeck College London, London, UK

${ }^{4}$ National Environmental Isotope Facility, British Geological Survey, Nottingham, UK

The global Shuram anomaly (c. 570 - c. $551 \mathrm{Ma}$ ) is the longest and most negative carbonate carbon isotopic excursion in Earth history with $\delta^{13} \mathrm{C}_{\text {carb }}$ values down to $-12 \%$. In South China, the Member IV of the Doushantuo Formation (c. 560-551 Ma) records the recovery from this anomaly, with values increasing from $-6 \%$ to $+0.5 \%$. The origin of this anomaly is thought to be related to the existence of a vast pool of dissolve organic carbon (DOC) in the ocean that was episodically oxidized thereby providing a source of ${ }^{13} \mathrm{C}$ depleted inorganic carbon. However, the main control(s) that ultimately drove its recovery remain elusive.

Here, we present new $\delta^{13} \mathrm{C}$ and $\delta^{15} \mathrm{~N}$ dataset along a shelfto-basin transect of the Nanhua basin to reconstruct the spatial and temporal evolution of paleoproductivity at basin scale. The observed increase in $\delta^{13} \mathrm{C}$ values together with a gradual decreasing shift in $\delta^{15} \mathrm{~N}$ values throughtout Member IV in platform and lower slope environments are interpreted as the establisment of a new equilibrium in the carbon cycle, where autotrophic biomass production surpassed heterotrophic consumption of dissolved organic carbon. Extensive primary productivity became the main source of organic matter in the system increasing the fraction of organic carbon burial and thus contributing to the carbon isotope recovery in carbonates. In addition, Raman spectroscopy is used to assess the thermal maturity and crystallinity of the organic matter, revealing a systematic difference in kerogen crystallinity between deeper and shallower environments that suggests different sources of biomass. This new paleoproductiviy scenario represents a plausible solution to the enigmatic negative $\delta^{13} \mathrm{C}_{\text {carb }}$ isotopic excursion of the late Ediacaran. 